\title{
EPIDEMIOLOGY OF GALL STONE DISEASE IN A TERTIARY CARE HOSPITAL- A CHANGING TREND IN CURRENT PERSPECTIVE
} \author{
Pankaj Srivastav ${ }^{7}$, Sneha Singh ${ }^{8}$ \\ ${ }^{1}$ Senior Resident, Department of General Surgery, SPS Apollo Hospital, Ludhiana. \\ ${ }^{2}$ HOD and Senior Consultant, Department of General Surgery, SPS Apollo Hospital, Ludhiana. \\ ${ }^{3}$ Senior Consultant, Department of General Surgery, SPS Apollo Hospital, Ludhiana. \\ ${ }^{4}$ Chief Dietitian, SPS Apollo Hospital, Ludhiana. \\ ${ }^{5}$ Senior Consultant, Department of General Surgery, SPS Apollo Hospital, Ludhiana. \\ ${ }^{6}$ Senior Resident, Department of General Surgery, SPS Apollo Hospital, Ludhiana. \\ ${ }^{7} 3^{\text {rd }}$ Year Resident, Department of General Surgery, SPS Apollo Hospital, Ludhiana. \\ ${ }^{8}$ MBBS Student, SPS Apollo Hospital, Ludhiana.
}

Pawan Kumar Singh ${ }^{1}$, Prafull Kumar Arya ${ }^{2}$, Harpreet Singh Khetarpal ${ }^{3}$, Kanika Goyal ${ }^{4}$, Harpreet Singh Jolly5, Tansila Din ${ }^{6}$,

\section{ABSTRACT}

\section{BACKGROUND}

Gallstones represent a significant burden for health care systems worldwide. Gallstones occur commonly in the western world. It is the leading cause of inpatient admissions for general surgical practice. The known epidemiology of gall stone like fat, fertile, female of forty seems to be changing now-a-days with shift towards thin young female patients and male sex.

\section{MATERIALS AND METHODS}

A total of 154 cholecystectomy procedures were performed in the time period between $15^{\text {th }}$ Jan 2014 and $14^{\text {th }}$ Jan 2015 in one year. All ultrasonographically proven gall stone disease patients undergoing cholecystectomy were included in our study. Out of 154 patients, 105 were female and 49 were male patients. All the included patients were interviewed with the help of questionnaire at the time of admission. Statistical analysis was performed using the SPSS Statistical Software Package. All values were expressed as percentage, mean \pm standard deviation (SD). The values were evaluated using student's ' $t$ ' test and Chi-square test was used for pair wise comparison and distribution significance.

\section{RESULTS}

Patients with gall stone disease are most commonly seen in thirties instead of forties as shown by numerous studies earlier. Male: female ratio is 1: 2.14, which has decreased from that described in earlier studies being 1: 4 to 1: 7. Maximum numbers of patients were overweight (BMI $25.00-29.99 \mathrm{~kg} / \mathrm{m}^{2}$ ) and normal category (BMI $18.5-24.99 \mathrm{~kg} / \mathrm{m}^{2}$ ) instead of obese persons (BMI $\geq 30.00$ $\left.\mathrm{kg} / \mathrm{m}^{2}\right)$ as seen in earlier studies. Family history of gall stone is not significantly associated $(\mathrm{p}>0.05)$ with gall stone disease. Parity of one or more was significantly associated $(\mathrm{p}<0.05)$ with gall stone disease in comparison to nullipara.

\section{CONCLUSION}

The present study revealed that the old known dictum that in a fat fertile female of forty presenting with right hypochondrium pain, always suspects of gall stone disease no more holds true in present scenario. The trend is changing with maximum patients presenting in their thirties with basal metabolic index (BMI) falling in overweight and normal category instead of obese along with narrowing male: female ratio. As at present there is trend of having two kids in the family, so parity of two being the commonest finding, the rule of multigravida being a predisposing factor no more holds true.

\section{KEYWORDS}

Gall Stone Disease, Risk Factors, Changing Trends.

HOW TO CITE THIS ARTICLE: Singh PK, Arya PK, Khetarpal HS, et al. Epidemiology of gall stone disease in a tertiary care hospitala changing trend in current perspective. J. Evolution Med. Dent. Sci. 2017;6(75):5332-5336, DOI: 10.14260/Jemds/2017/1158

\section{BACKGROUND}

Gall stones have been reported in Egyptian mummies and this indicates that the disease has existed for more than 35 centuries dating back to 1000 BC.(1) Gallstones represent a significant burden for health care systems worldwide. Gallstones occur commonly in the western world.(2-7)

Financial or Other, Competing Interest: None.

Submission 12-08-2017, Peer Review 05-09-2017,

Acceptance 11-09-2017, Published 18-09-2017.

Corresponding Author:

Pawan Kumar Singh,

Room No. 52, Doctor's Hostel,

SPS Hospital, Sherpur Chowk,

Ludhinana-141003.

E-mail:pa1.life009@gmail.com

DOI: $10.14260 /$ jemds $/ 2017 / 1158$

\section{(c) $(1) \ominus$}

It is the leading cause of inpatient admissions for general surgical practice.(8) The known epidemiology of gall stone like fat, fertile, female of forty ${ }^{(9)}$ seems to be changing now-a-days with shift towards thin young female patients(10) and male sex. $(11,12)$

The aetiology of cholesterol stones is considered multifactorial with interaction of genetic and environmental factors. Most exogenous factors are a consequence of the westernisation of modern societies. Depending on their composition, gallstones are often divided into three major types: cholesterol, black pigment and brown pigment stones. Black pigment stones are more common among patients with haemolytic diseases (Hereditary spherocytosis, sickle cell anaemia and thalassaemia) and liver cirrhosis. Brown stones are often caused by stasis and infection in the biliary system. In the Western world, the major constituent of gallstones is 
cholesterol which comprises $50 \%-98 \%$ of the dried substance of the stone. Other constitutes may include fatty acids, triglycerides, proteins, polysaccharides, bacteria as well as calcium bilirubinate, calcium carbonate and calcium bicarbonate. Gallbladder stones vary in size from less than a millimetre up to a few centimetres in diameter. In 10\% - 15\% patients with gall stone, the stone migrates into common bile duct also. For cholesterol stones the modifiable risk factors are obesity, rapid weight loss, diet, alcohol abstinence, decreased physical activity, smoking, medications (i.e. oral contraceptive pills, octreotide), hyperlipidaemia and diabetes mellitus type II. The non-modifiable risk factors for cholesterol stones are female gender, age and genetics. Asymptomatic gallstone disease is being increasingly diagnosed today as a result of widespread use of ultrasonography in the evaluation of patients with abdominal complaints. Abdominal symptoms are common both in subjects with gallbladder stones and the population in general. Right upper quadrant pain during the night was found to be the most specific symptom in men. Severe pain provoked by fatty meals to be the symptom best correlating with the presence of gallstones in women. Other digestive symptoms such as food intolerance, acid regurgitation, heartburn, bloating, nausea and vomiting which are also common in the general population often co-exist among persons with gallstone disease.

\section{MATERIALS AND METHODS}

A hospital-based, prospective, observational study was carried out in the Department of General Surgery at Satguru Partap Singh Apollo Hospitals, Ludhiana for 1 year (from 15th Jan 2014 to $14^{\text {th }}$ Jan 2015). A total of 154 cholecystectomy procedures were performed in the time period between $15^{\text {th }}$ Jan 2014 and $14^{\text {th }}$ Jan 2015 falling under-

\section{Inclusion Criteria}

Which included all patients with ultrasonographically proven gall stone disease undergoing cholecystectomy in our hospital in our study.

\section{Exclusion Criteria}

Included all patients with history of haemolytic disorder, previous surgery (major bowel resection), prolonged hospitalisation, history of long duration of total parenteral nutrition, cystic fibrosis, spinal cord injury, psychiatric patient and patient's refusal.

All ultrasonographically proven cases of cholelithiasis that fall in inclusion criteria of study were interviewed with the help of questionnaire at the time of admission regarding: Personal information like name, patient ID, address, occupation, age, gender, nationality, educational qualification, socio-economic status using updated 2013 Kuppuswamy's socio-economic scale.(13) BMI was calculated and patients were to be further classified according to the WHO classification.(14) Ultrasound of the whole abdomen was done after a fasting period of at least 6 hours by a radiologist, who did not have information about the patient, in supine and left lateral position. All patients were inquired about their symptoms related to gall stone disease, about family history of gall stone disease, their parity, past and present medical history in relation to diabetes mellitus, haemolytic disorder, hypercholesterolaemia, hypertriglyceridaemia and any other if present. They were also inquired if they had undergone any previous surgical procedure. History of prolonged total parenteral nutrition; history of weight loss; any medications like oral contraceptive pills, octreotide, fibrates, thiazides; history of alcohol, smoking, opium or any other addictions was noted. Investigations including basic surgical workup and other relevant investigations related to medical comorbidities like diabetes mellitus, hypertriglyceridaemia and hypercholesterolaemia were done prior to surgery. Triglyceride and cholesterol levels were checked after overnight fasting. Nutrition assessment was done through questionnaire and dietary recall was done using three days 24-hour recall method and nutritional value was to be calculated as per ICMR food standards. Chief dietician in our hospital was involved in study for the dietary assessment.

\section{Brief Explanation about Risk Factors}

\section{(A) Cholesterol Stones}

\section{(1) Unmodifiable Risk Factors}

(a) Gender: Generally, gallstone disease is more prevalent in females than in males. However, these differences of gallstone incidence between sexes decreases with advancing age. According to the Group for Epidemiology and Prevention of Cholelithiasis (GREPCO) study, the female-to-male ratio for gallstone disease was 2.9 between 30 and 39 years of age, 1.6 between 40 and 49 years of age, and 1.2 between 50 and 59 years of age. Female sex hormones appear to play a role, especially between the ages of 20 and 30 years. Another study that researched oestrogen receptors and cholesterol biosynthesis found that oestrogen in particular stimulated the HMG-Co-A reductase enzyme causing increased synthesis of cholesterol and thus putting women at an increased risk of supersaturation. Further supporting the link between oestrogen and gallstones, it was determined that postmenopausal women on oestrogen replacement therapy were found to have an increased incidence of gallstones. Progesterone may also contribute to gallstone disease by inhibiting gallbladder contraction and promoting hypomotility and gallbladder stasis. Parity also appears to be a factor in the development of gallstones. Women with more pregnancies and longer lengths of fertility periods appear to have a higher likelihood of developing gallstones than those who remain nulliparous. A study in Chile found gallstones in $12.2 \%$ of multiparous women versus $1.3 \%$ of nulliparous women within the same age. Another study found women under the age of 25 years with $\geq 4$ pregnancies were 4 to 12 times more likely to develop cholesterol stones compared to nulliparous women of the same age and weight. It should be noted that biliary sludge usually disappears a few weeks after the pregnancy concludes/terminates/ ends.

(b) Age: Age also appears to have an effect on the incidence of gallstone disease. Gallstone disease before 20 years of age is a rare occurrence. In infants and children, the most common stones are pigment stones, which are related to haemolysis or chronic diseases such as cystic fibrosis, thalassaemia major and sickle cell anaemia. Typically, only $0.15 \%$ to $0.22 \%$ of children will have gallstones and children account for less than $5 \%$ of all 
cholecystectomies. The increased incidence of gallstones with age is seen across all ethnic groups. A Danish study also showed that an increased incidence of gallstone disease in patients $\geq 45$ years compared with those aged $\leq 35$ years, while the differences in gallstone incidence between sexes decreased with advancing age. From a biochemical standpoint, age itself may increase cholesterol saturation of bile with enhanced hepatic secretion of cholesterol secondary to increased levels of HMG co-A reductase, the ratelimiting enzyme of cholesterol synthesis. Decreased synthesis of bile acids may occur secondary to decreased cholesterol 7 a-hydroxylase enzyme activity, the rate-limiting enzyme in bile acid synthesis as age advances.

(c) Genetics: It remains to be determined the exact role of genetics in the occurrence of gallstones that would account for the different prevalence rates among the different ethnic groups. However, genetic makeup appears to contribute to the prevalence of cholelithiasis, as there is wide variation in incidence between different ethnicities. For example, the Pima tribe of Arizona has the highest prevalence of gallstone disease in the world, where an estimated $73 \%$ of women > 25 years have cholelithiasis with the prevalence rising to $90 \%$ by $\geq 65$ years.(15) In South America, the prevalence of gallbladder disease among Mapuche Indians of Chile is $49 \%$ in women and $13 \%$ in men. In the United States, the NHANES III survey showed a higher prevalence of gallstones in MexicanAmericans compared to non-Hispanic whites, while American blacks had the lowest prevalence. In Europe, the highest prevalence of gallstone disease was found in Norway (21\%) and the former East Germany (19\%), while the lowest incidence was found in Italy (6\%). In Asian countries, the prevalence of cholesterol gallstones is relatively low. These countries and populations are being more commonly associated with pigment stones. In northern India for example, the prevalence of cholelithiasis is about $6 \%$. However, with the increased expansion of the Western diet throughout the world the number of stones attributed to cholesterol is expected to increase. In individuals, studies have shown that genetic factors are responsible for at least $30 \%$ of symptomatic gallstone disease. It has been found that monozygotic twins have been shown to have a higher cholesterol saturation index than dizygotic twins. Furthermore, a study in Europe found linked mutation in the ABCG8-gene with the occurrence of gallstones, as this mutation was carried in $21 \%$ of 178 men and women with gallstones. It was found that this mutated gene was responsible for the "pump," which transported blood lipid cholesterol from the liver into the bile ducts, therefore increasing the formation of cholesterol gallstones.

\section{(2) Modifiable Risk Factors}

(a) Obesity: Obesity is an important risk factor for the development of gallstone disease. Obese women, defined as a body mass index (BMI) $>30 \mathrm{~kg} / \mathrm{m}^{2}$ are at twice the risk of gallbladder disease than women with a normal BMI $\left(<25 \mathrm{~kg} / \mathrm{m}^{2}\right)$. Women with extreme obesity or a BMI $>40 \mathrm{~kg} / \mathrm{m} 2$ have a 7 -fold increased risk of gallstones. The reason for the increased risk of gallstones in obese patients is due to an increased hepatic secretion of cholesterol. Additionally, the correlation between gallstone disease and obesity is greater with those patients with central obesity and those who developed obesity at an early age rather than in the later years of life.

(b) Rapid Weight Loss: Rapid weight loss is another risk factor for gallbladder disease, as demonstrated by the Nurses' Health Study, which followed close to 90,000 women. This study found that women who lost $4 \mathrm{~kg}$ to $10 \mathrm{~kg}$ of weight over a 2-year interval had a $44 \%$ increase in the risk for gallstone disease as compared with women whose weight changed $<4 \mathrm{~kg}$ over the same time period. Furthermore, women who lost $>10$ $\mathrm{kg}$ of weight had a $94 \%$ increase in the risk for gallstone disease as compared with women whose weight change was $<4 \mathrm{~kg}$ when controlling for BMI and other risk factors for gallstones. Another study demonstrated that a weight loss $>1.5 \mathrm{~kg} /$ week led to a dramatic increase in the risk of gallstone formation. It has also been shown that sludge and gallstones develop in 25\% - 35\% of extremely obese patients with weight loss secondary to bariatric surgery, usually during the first 6 weeks following surgery when weight loss is most profound.

(c) Diet and Activity: Closely related to obesity and rapid weight loss are diet and physical activity. Diets that encompass Vitamin C, moderate alcohol intake, coffee and nut consumption lower the incidence of gallstone disease. Conversely, increased cholesterol intake and low fibre diet, typical of Western diets are predisposing risk factors for the development of gallstone disease. Total parenteral nutrition (TPN) also increases the risk of gallstone occurrence as demonstrated by a study that found that the incidence of cholelithiasis was $6.2 \%$, $21.2 \%$ and $38.7 \%$ at 6,12 and 24 months of receiving TPN, respectively. With regard to physical activity, decreased activity increases the risk of gallstones, while many forms of activity including vigorous or brisk walking, protect against gallstone disease.

(d) Smoking, Medications, Hyperlipidaemia, Diabetes Mellitus II: There also appears to be a very weak relationship between gallstones and other common medical conditions such as chronic obstructive pulmonary disease (COPD) and coronary artery disease (CAD). Paradoxically, hyperlipidaemia is only tenuously linked to gallstones. Although, low levels of highdensity lipoprotein (HDL) cholesterol and high triglycerides are associated with gallstone disease, the extent to how much the risk is increased has not clearly been defined by any major study. Other diseases such as diabetes mellitus seem to facilitate the development of gallstone formation secondary to increased triglyceride levels associated with obesity as well as promoting gallbladder hypomotility and stasis. A study in Japan showed a moderate increase in the risk of gallstones in patients with diabetes mellitus; however, there is no conclusive link between these two conditions. Smoking is even less convincingly linked to increased risk of gallstone disease. A multitude of various medications have been linked to the 
development of gallstones. These include thiazides, oral contraceptives and ceftriaxone. Somatostatin is also associated with gallstone development, because of its effect on impaired gallbladder emptying.

(2) Pigment Stones

Briefly, there are 2 types of pigment gall stones: black and brown gallstones. Black pigment stones are predominantly composed of an insoluble bilirubin pigment polymer mixed with calcium phosphate and carbonate. Precipitation of calcium bilirubinate occurs whenever the ionic product of calcium and unconjugated bilirubin exceeds its solubility product. The major factors causing black pigment stones are haemolytic anaemias, ineffective erythropoiesis and increased production of bilirubin (caused by hereditary spherocytosis, thalassaemia, sickle cell disease, liver cirrhosis, malaria and ineffective erythropoiesis). Factors causing absorption of bilirubin from gut include ileal resection or ileal disease, liver cirrhosis, total parenteral nutrition and cystic fibrosis. ${ }^{13}$ Most of the brown pigment stones are formed in the bile ducts as a consequence of some infection and stasis of bile flow. Chemically, they are calcium salts of long chain fatty acids and cholesterol. Bacterial $\beta$-glucuronidase deconjugates bilirubin diglucuronide into insoluble unconjugated bilirubin, which precipitates in the bile duct. Any factor that interrupts normal bile flow predisposes to infection and subsequently to brown pigment stone formation as is observed with biliary strictures, periampullary diverticulum and Caroli syndrome. Intrahepatic brown pigment stones are seen with infestation of bile ducts with Ascaris lumbricoides and Clonorchis sinensis.

\section{RESULTS}

A total of 154 cholecystectomy procedures were performed in the time period between $15^{\text {th }}$ Jan 2014 and 14th Jan 2015 in one year. All ultrasonographically proven gall stone disease patients undergoing cholecystectomy were included in our study. Out of 154 patients, 105 were female and 49 were male patients. Statistical analysis was performed using the SPSS Statistical Software Package. All values were expressed as percentage, mean \pm standard deviation (SD). The values were evaluated using student's ' $\mathrm{t}$ ' test and Chi-square test was used for pair wise comparison and distribution significance.

\section{Age Distribution}

The age distribution in our study is shown in Table 1, which reveals maximum numbers of patients were in $31-40$ years of age and the percent of patients decreases with increasing age. Mean age in male was $38.51 \pm 8.732$ years and in females the mean age was $38.87 \pm 9.538$ years.

\begin{tabular}{|c|c|c|c|c|c|c|}
\hline \multirow{2}{*}{$\begin{array}{c}\text { Age } \\
\text { (Years) }\end{array}$} & \multicolumn{5}{|c|}{ Sex } & \multirow{2}{*}{ Total } \\
\cline { 2 - 7 } & Nomale & \% Age & No. & \% Age & No. & \% Age \\
\hline $11-20$ & 0 & 0.00 & 1 & 2.04 & 1 & 0.65 \\
\hline $21-30$ & 16 & 15.24 & 8 & 16.33 & 24 & 15.58 \\
\hline $31-40$ & 54 & 51.40 & 19 & 38.78 & 62 & 40.26 \\
\hline $41-50$ & 21 & 20.00 & 15 & 30.61 & 43 & 27.92 \\
\hline $51-60$ & 10 & 9.50 & 6 & 12.24 & 20 & 12.99 \\
\hline $61-70$ & 4 & 3.81 & 0 & 0.00 & 4 & 2.60 \\
\hline Total & 105 & 100.00 & 49 & 100.00 & 154 & 100.00 \\
\hline \multicolumn{7}{|c|}{ Table 1 } \\
\hline
\end{tabular}

\section{Sex Distribution}

The sex distribution in our study is shown in Table 2, which reveals maximum number of patients were females with male: female ratio was $1: 2.14$. We found female sex to be significantly associated with gall stone disease.

\begin{tabular}{|c|c|c|}
\hline Sex & No. of Cases & Percent \\
\hline Female & 105 & 68.2 \\
\hline Male & 49 & 31.8 \\
\hline Total Patients & $\mathbf{1 5 4}$ & $\mathbf{1 0 0 . 0}$ \\
\hline \multicolumn{3}{|c|}{ Table 2 } \\
\hline
\end{tabular}

\section{Basal Metabolic Index (BMI)}

The distribution of BMI in our study is shown in Table 3, which reveals that the maximum numbers of patients were overweight instead of obese category, as per WHO category. The mean BMI of overall patients was $26.63 \pm 3.365 \mathrm{~kg} / \mathrm{m}^{2}$. In females, the average BMI is $26.73 \pm 3.569 \mathrm{~kg} / \mathrm{m}^{2}$ and in males the average BMI is $26.40 \pm 2.90 \mathrm{~kg} / \mathrm{m}^{2}$. In our study we found high BMI ( $>30)$ was not significantly associated, but instead a low BMI $(<30)$ which was significantly associated with gall stone disease.

\begin{tabular}{|c|c|c|}
\hline $\begin{array}{c}\text { Basal Metabolic Index (BMI) } \\
\text { WHO Category }\left(\mathbf{k g} / \mathbf{m}^{\mathbf{2}}\right)\end{array}$ & No. of Cases & Percent \\
\hline Normal $(18.5-24.99)$ & 53 & 34.4 \\
\hline Overweight $(25-29.99)$ & 80 & 51.9 \\
\hline Obese class-1 $(30-34.99)$ & 17 & 11.0 \\
\hline Obese class-2 $(35-39.99)$ & 3 & 1.9 \\
\hline Obese class-3 $(\geq 40.0)$ & 1 & .6 \\
\hline Total & $\mathbf{1 5 4}$ & $\mathbf{1 0 0 . 0}$ \\
\hline \multicolumn{2}{|c}{ Table 3 } \\
\hline
\end{tabular}

\section{Parity}

The parity distribution in our study is shown in Table 4, which reveals that in our study parity of one or more was significantly associated with gall stone disease in comparison to nullipara. Maximum patients had parity of 2 and we did not find increasing trend with increasing number of pregnancies.

\begin{tabular}{|c|c|c|}
\hline Parity & No. & Percent \\
\hline 0 & 4 & 3.8 \\
\hline 1 & 36 & 34.3 \\
\hline 2 & 40 & 38.1 \\
\hline 3 & 19 & 18.1 \\
\hline 4 & 6 & 5.7 \\
\hline Total & $\mathbf{1 0 5}$ & $\mathbf{1 0 0 . 0}$ \\
\hline \multicolumn{3}{|c|}{ Table 4 }
\end{tabular}

\section{DISCUSSION}

Gallstone disease remains a common health problem for human beings, affecting millions of people throughout the world. Gall stones are the most common biliary pathology, $10 \%-15 \%$ of adult population in the USA have gallstones. Its incidence varies from as high as $60 \%$ in Pima Indians over 35 years of age to as low as $3.2 \%$ in Japanese women.(15) Gall bladder disease was said to be the disease of women with known dictum that in a fat fertile female of forty presenting with right hypochondrium pain, always suspect gall stone disease. However, a change in this pattern is perceived in this part of the world, Gupta RL et al ${ }^{(10)}$ found that young asthenic females in their mid-twenties are commonly suffering from 
gall stone disease. Shah $\mathrm{T}$ et al(11) and Shenoy AK et al(12) even showed preponderance towards male sex in their studies.

Various studies from India show high prevalence of gall stones in India with varying prevalence noted from different part of country. Several studies from New Delhi and one study done at PGI Chandigarh confirm the high number of gallstone disease in North India.(16,17)

There has only been one study from northern India to see the changing trends in pattern of gall stone disease.(10) Therefore, our intention for this study was to find out the changing trends in gall stones disease pattern in our institution over a period of one year by enrolling patients falling in the inclusion criteria.

This change may be due to more use of ultrasound as an extension of clinical examination and awareness among people towards their health related issues. In our study, we found that the trend is changing with maximum patients presenting in their thirties with basal metabolic index (BMI) falling in overweight and normal category instead of obese along with narrowing male: female ratio.

\section{CONCLUSION}

The present study revealed that the old dictum that in a fat fertile female of forty presenting with right hypochondrium pain, "always suspect gall stone disease," no more holds true in present scenario. The trend is changing with maximum patients presenting in their thirties with basal metabolic index (BMI) falling in overweight and normal category instead of obese along with narrowing male: female ratio. As at present there is trend of having two kids in the family, so parity of two being the commonest finding, the rule of multigravida being a predisposing factor no more holds true.

\section{REFERENCES}

[1] Njeze GE. Gallstones. Niger J Surg 2013;19(2):49-55.

[2] Attili AF, Carulli N, Roda E, et al. Epidemiology of gallstone disease in Italy: prevalence data of the multicenter Italian study on cholelithiasis (M.I.COL.). Am J Epidemiol 1995;141(2):158-65.

[3] Diehl AK. Epidemiology and natural history of gallstone disease. Gastroenterol Clin North Am 1991;20(1):1-19.

[4] Barbara L, Sama C, Labate MAM, et al. A population study on the prevalence of gallstone disease: the sirmione study. Hepatology 1987;7(5):913-7.
[5] Jorgensen T. Prevalence of gallstones in a Danish population. Am J Epidemiol 1987;126(5):912-21.

[6] Kratzer W, Kächele V, Mason RA, et al. Gallstone prevalence in Germany: the Ulm gallbladder stone study. Dig Dis Sci 1998;43(6):1285-91.

[7] Loria P, Dilengite MA, Bozzoli M, et al. Prevalence rates of gallstone disease in Italy: the Chianciano population study. Eur J Epidemiol 1994;10(2):143-50.

[8] Russo MW, Wei JT, Thiny MT, et al. Digestive and liver diseases statistics, 2004. Gastroenterology 2004;126(5):1448-53.

[9] Friedman GD, Kannel WB, Dawber TR. The epidemiology of gallbladder disease: observations in the Framingham study. J Chron Dis 1966;19(3):27392.

[10] Gupta RL, Sharma SB, Kumar SP, et al. Changing trends (clinico-biochemical) in gall-bladder stone disease-an observation. Indian J Med Sci 1998;52(7):309-16.

[11] Shah T, Shah P, Parmar H, et al. Prospective single center study of 100 patients undergoing laparoscopic cholecystectomy- changing trends. NHL J Med Sci 2013;2(1):61-4.

[12] Shenoy UA, Nayak MN, Shenoy MG, et al. Cholelithiasis in Manipal. Indian J Med Res 1982;76:454-7.

[13] Vijaya K, Ravikiran E. Kuppuswamy's socio-economic scale-updating income ranges for the year 2013. National J Res Comm Med 2013;2(2):79-148.

[14] World Health Organisation 2006. BMI classification. http://www.who.int/bmi/index.jsp?introPage=intro_ 3.html.

[15] Sampliner RE, Bennett PH, Comess LJ, et al. Gallbladder disease in pima indians. Demonstration of high prevalence and early onset by cholecystography. N Engl J Med 1970;283(25):1358-64.

[16] Singh V, Bandana T, Chanderkanwal N, et al. Epidemiology of gallstone disease in Chandigarh: a community based study. J of gastroenterol 2001;16(5):560-3.

[17] Sharma MP, Duphare HV, Nijhawan S, et al. Gallstone disease in North India: clinical and ultrasound profile in a referral hospital. J Clin Gastroenterol 1990;12(5):547-9. 